\title{
Cost Control in the Design Stage of Construction Engineering
}

\author{
Duan Shixia, Diao Jielin \\ School of Management Engineering, Zhengzhou University, Zhengzhou, China \\ 13693741875@163.com
}

Keywords: Project design; Cost control; Value engineering

\begin{abstract}
From the perspective of cost control, the design phase is the key stage of investment control of construction projects. It stipulates the construction scale and construction standards. At the same time, it also determines the scale of investment in construction projects. At present, domestic cost management work is constantly improving and developing, but there are still many problems in actual operation. In view of the problems existing in the cost control of the current domestic building planning scheme, this paper analyzes some influencing factors of the cost control in the current design stage, and finally gives specific measures for the cost control in the design stage. This paper combines the actual scheme, analyzes the impact of different design schemes on the total cost of the project, and optimizes the design scheme by using the value engineering principle to obtain the optimal economic and social benefits.
\end{abstract}

\section{Introduction}

Under the new situation, how to be invincible in the fierce market competition has become the focus of research in various construction enterprises. The whole process management of the project includes decision-making, design, construction, production preparation, completion and other stages. The design phase is most closely related to other links, and is the core stage in the whole project. The higher the quality of a project's design, the greater the probability that the project will succeed. The most critical task in the design phase is to optimize the design and do the evaluation. Therefore, in order to adapt to the development of society, improve the quality of building products, to bring higher economic benefits to the enterprise, and to strengthen the cost control work in the design stage of the project is particularly important.

According to the analysis of the cost control in the design stage of architectural planning scheme, domestic and foreign scholars have also put forward some opinions, and have their own analysis and views. Scholars pointed out, the cost control from the design preparation stage to the design stage reflects the idea of ex ante control, which is the key link for effective control of construction investment, and it belongs to active control (Xiaoli Chen, 2015). In addition, there are some problems in the design stage pricing model, which leads to a lack of awareness and innovation for designers (Jianhua Ma, 2015). The construction unit generally pays the design cost as a percentage of the total project cost or according to the floor area. Designer rarely considers the economics and rationality of the cost, and more is to meet the security and functionality required for the project. 
Designers should correctly deal with the relationship between cost and design. In the design phase, they should consider economic and technical factors, strengthen the awareness of cost control in the design stage of all parties, and gain the initiative in cost control. The cost engineer is a direct participant in the project cost management work, and their comprehensive quality directly affects this work (Lingling Cheng, 2015). However, the staff with high comprehensive quality, strong work ability and high professional ethics are scarce.

The structure of this paper is: Firstly, this paper introduces the background of the topic selection, and introduces the status quo of cost management at the domestic and international design stage. Secondly, it analyzes the influencing factors and existing problems of cost control in the design stage. Finally, give specific measures and methods for cost control, and point out the importance of the preferred scheme. Combined with the actual case, take a residential building in a certain district as an example, the impact of different design schemes on the project cost is deeply studied and analyzed. The use of value engineering principles to select the optimal solution, thus verifying the necessity of cost control in the design phase.

\section{Problems in Cost Control During The Design Phase of the Project}

The design phase is the key link that affects and controls the total cost of construction projects. Due to some inherent cognition, people generally neglect the early stage of project construction, and focus on cost control in the later stage of project construction, pay more attention to the construction phase vinal settlement stage of construction projects and so on, lack of in-depth research on cost control in the design phase of the project, these reasons have caused a waste of investment in engineering projects. The problems in the cost control of the design stage mainly include:

\subsection{Less Management Constraints in the Biddling Stage}

Nowadays, lots of engineering projects, when designing the scheme in the feasibility study stage, only rely on the design experience of similar engineering projects in the past to make judgments easily. Due to incomplete consideration of various aspects, the quality of the design scheme cannot meet the requirements. In addition, the quality of the designer is not up to the requirements. In many cases, designers in order to design a unique building, it is vigorously pursuing formalization, blindly matching the architectural plan, but little consideration is given to the cost and technical feasibility of the construction plan.

\subsection{Separation of Technology from Economy in the Design}

In the field of engineering cost budget in China, the relationship between economic application and technological advancement is often conflicting. From the design side, the designer only undertake the technical and security risks of the project itself, and the investment risk is borne by the owner, which leads the design unit to pay attention to the advanced technology and safety reliability, insufficient consideration of the economic rationality of the design. This brings difficulties to the cost control of the design stage. Lack of effective communication between departments in the whole process of project management, the separation of technology and economy, this caused a waste of investment.

\subsection{Lack of Constraints on Design Change}

There are some uncertainties in the whole process management of construction engineering 
projects, and design change often happen during the construction process. For example, changes required by the owner, the design side may not be fully considered and so on. In these respects, lack of management in relevant departments, unclear division of responsibilities, which will be affect the project cost.

\subsection{Uneven Quality of Designers}

The designer is the implementer of the design phase, the quality of the designer greatly affects the project cost. On the one hand, some construction units think that the cost control during the construction phase is far more important than the design phase, pay more attention to the construction stage. These construction units considered simplicity in the design stage of the project, and the supervision of the design unit is weak. On the other hand, the design unit is arbitrarily flexible, the designers lack a clear evaluation system for their own design results. Although the designer will conduct an audit review, just found some surface problems through the drawings, deep problems are only discovered when they appear, which will bring great difficulty to cost control.

\section{Influencing Factors of Cost Control in the Design Stage of the Project}

There are many factors influencing the cost control in the design stage of the building planning scheme, which can be summarized as the following aspects:

\subsection{Plane Layout}

Generally, the more regular the plane shape of the building, the lower the cost. If the building is irregular, it will increase the workload of the next process and increase the difficulty of construction. It is generally reflected in the engineering cost of electrical engineering, drainage engineering, roofing engineering, masonry engineering, etc. From the engineering practice, arranging buildings in rectangles or squares reduces costs. If the plane is arranged in a rectangular shape, it is preferable that the aspect ratio is less than 2 .

\subsection{Building Structure}

In the process of building a house, Building structure refers to a system composed of various components (roof, beam, slab, column, etc.) capable of withstanding various functions. The role of building structure refers to various factors that can cause internal force and deformation of the system, such as load, earthquake, temperature change and foundation settlement.

(1)The choice of structural form

According to the materials used, the building structure can be divided into concrete structure, steel structure, masonry structure and wood structure. When the design unit determines the structural form, it should strengthen the review and survey of the ground conditions on the site, and combine the actual demand of the owner, try to choose a low-cost structure to achieve rational allocation of resources. Analysis of relevant data shows that the masonry mechanism is more economical than the reinforced concrete structure in regular buildings below five floors. For the framed parts of multi-storey office buildings and high-rise apartment buildings, it is more reasonable to choose a concrete structure.

(2) Basic design

Generally speaking, the construction period of the basic project accounts for $25 \%-30 \%$ of the total construction period of the main building project, and the construction cost of the basic part accounts for $10 \%-20 \%$ of the total project cost. The cost of the basic part is mainly related to the 
geological conditions of the project site. On the one hand, the basic engineering has a great impact on the total cost of the project; On the other hand, the basic engineering is also the main bearer of the structural load of the entire building. Unreasonable design of the above-ground standard layer will greatly increase the total cost. When designing the basic project, the designer should communicate with the construction party in time, and complete the work of the geological exploration report, comprehensively consider various factors, finally choose the appropriate basic form.

(3) Structural members of the superstructure

The superstructure of the building is another major subject of cost control. When designing the superstructure, reasonable choice of building materials and scientific design of component size is an effective way to reduce cost. The use of lightweight materials in the design can simplify the process and save costs. The design of structural members is also an important part of cost control. The strength grade of steel bars, the size of column beams and the performance of concrete may affect the cost control. Under the premise of meeting the structural design standards, some necessary measures can be taken to reduce the cost, such as reducing the section size of the components, and using HRB400 steel bars.

\subsection{Selection of Building Materials}

With the rapid development of the construction industry, the proportion of building materials used in the construction process to the total cost is still increasing, even up to $50 \%-70 \%$. The ability to choose the right building materials is not only related to the quality and safety of the entire project, but also affects the total cost of the project to a large extent. In recent years, new materials have gradually emerged and become more and more popular, the main reason is that these new building materials not only can increase building functions, expand space, but also can improve building quality.

\section{Measures for Cost Control in the Design Stage}

The measures that can be taken to strengthen the cost control in the design stage of the project are mainly:

\subsection{Establish the Necessary Design Competition Mechanism}

In the construction of engineering projects, the construction unit generally adopts the bidding system to determine the design unit. (Qunhui Liu, 2011) In order to refine the bidding workflow, the construction unit should require the designer to provide the plan design estimate when conducting the program selection, clarify the budget control indicators, the set criteria should be combined with technical indicators and economic indicators, and comprehensive consideration of various factors. In addition, the necessary design competition mechanism should be established within the design unit, strictly comply with ISO standards, encourage and reward advanced technology and functional construction programs, focus on strengthening the sense of competition among designers, enhance internal competitiveness.

\subsection{Actively Implement Quota Design, Control Costs Reasonably}

Quota design is the design that satisfies technical requirement in accordance with the project investment or cost limit. The quota design mainly includes two aspects. On the one hand, the next stage of the project meet the design technical requirements according to the investment or cost limit 
of the previous stage. On the other hand, part of the project according to the set investment or cost limit to meet the design technical requirements.

Designers and cost engineer should first ensure that the owner's funds can be used correctly, optimized design by design scheme, equipment selection, parameter matching, benefit analysis, etc. According to the approved investment estimate, preliminary design estimates, analysis of the investment composition and engineering volume of the project, control the cost limit of individual projects, design a preliminary design scheme with reasonable technical economy.

\subsection{Accelerate the Design Supervision System}

The quality of the design is directly related to project quality and project cost. For the sustainable development of the construction industry, government departments should speed up the design supervision system and strict control of the design process. By speeding up the system of design supervision can break the single situation of self-restraint of design unit. Government departments should strengthen the supervision of industries and trade unions, and strengthen the introduction, training and assessment of relevant supervision talents, actively issue relevant powers and responsibilities documents for design supervision work, thus realizes the acceleration advancement design supervision system. Relevant departments can also promote the optimization design work by compulsory review of design results, so as to provide strong support for the socialization and marketization of design supervision.

\subsection{Improve the Professionalism of Designers}

Firstly, designers should improve their business level and comprehensive quality, familiar with construction project budget quota and cost quota, and keep abreast of the industry's cutting-edge dynamics to adapt to the competitive market environment. Secondly, the design unit should strengthen the quality consciousness of the designer, pay attention to the needs of the owners, and maximize the professional advantages of the designers. Finally, in the design of architectural planning schemes, designers should proceed from the overall interests and communicate with the cost engineer in a timely manner. Under the premise of ensuring the quality of the project, reduce the cost of the preliminary design estimate.

\section{Case Analysis}

\subsection{Project Overview}

The proposed project is a multi-storey residential community with a total site area of approximately 50,000 square meters. The community has a total of 3 buildings, each with 11 floors, and each with a height of 3.2 meters. The geological conditions of the plot are good, the site is regular, the materials are convenient, and the construction is convenient. The community has two main entrances and exits, and there are more than 700 parking spaces in the underground parking lot. The greening rate is $30 \%$ and the floor area ratio is 1.7 . For the structural design of this project, in the basic design, the reinforced concrete raft foundation will be used to meet the strength and deformation requirements. In terms of the selection of the superstructure, the design project has a design life of 50 years, the house safety level is 2, the seismic fortification intensity is 7 degrees, and the main structure is a frame structure. 


\subsection{Using the Principle of Value Engineering Optimization}

(1) The basic concept of value engineering and the optimization approach

The construction unit selects a design unit by means of design bidding, and optimizes the design scheme by using the value engineering principle. Research shows that the value engineering theory stage plays the most important role in the design stage. After all, it is easy to modify the design plan at this stage, and it will not cause too much economic loss.

The expression for the value analysis method is:

$$
\mathrm{V}(\text { Value })=\frac{F(\text { Function })}{C(\text { Cost })}
$$

When $\mathrm{V}<1$, the design cost is high, and there are some unnecessary functions; When $\mathrm{V}>1$, the design cost is low, this means that the function is imperfect; When $V=1$, the function and cost design are reasonable and the effect is optimal.

In general, we can increase product value by adjusting cost inputs, replacing functional requirements, and so on. It is particularly important to note that when using the value engineering principle for value analysis, we cannot blindly pursue cost reduction or function improvement, but study the optimal configuration of the two.

(2) The main work content of value engineering in program design optimization

The main work contents of value engineering in design scheme optimization are: object selection, system analysis of function, function evaluation, scheme creation and evaluation, scheme implementation and evaluation. After the above workflow, according to the collected data, calculate the function weight coefficient, function evaluation coefficient and cost evaluation coefficient according to the collected data. Finally, calculate the value coefficient, and the scheme with the largest value coefficient is the optimal scheme.

\subsection{Calculation Function Factor F}

Experts and reviewers have given several factors that primarily influence the function of the program, including structural type, formwork type, wall material, floor plan, and environmental protection. The construction unit will adopt the opinions of the designer, the construction side and the users. Their weight coefficients are $0.3,0.2$ and 0.5 respectively. The main body of each factor will use the percentage system to score, and the relevant staff will first calculate the function weight coefficient, and then use the ten system to score each program, finally calculate the function coefficient. The final result of the integrated design party score, the construction party score, the user score can be derived: the weight coefficient of the function type is 0.196; the weight coefficient of the function type of the template is 0.206; the weight coefficient of the function is wall material 0.234; the weight coefficient of the function is the plane arrangement 0.196; the weight coefficient of the function for environmental protection is 0.148 .

Based on the above data: the two important functional requirements of the residential project are wall material, floor plan, and the calculation results are consistent with the initial setting of the project. Moreover, it can be seen from the table, due to the influence of other objective factors, we must select the type of structural model to protect the environment and maximize the utilization rate.

\subsection{Program Creation and Evaluation}

After doing the above work, the Value Engineering Team carefully understood the residents' requirements for residential living conditions and went to the site to observe the local natural 
conditions and made address exploration. After in-depth research and analysis, they concluded that the foundation conditions are good, the groundwater level is deep, strong and can withstand large loads. Finally, after consulting the various parties, the Value Engineering Team gave three options. As shown in Table 1:

Table 1 Program characteristics.

\begin{tabular}{|c|c|c|c|}
\hline Program & structural feature & Cost factor & $\begin{array}{c}\text { Cost per square } \\
\text { unilateral }\end{array}$ \\
\hline Option One & Brick structure & $\begin{array}{c}\text { Double glass hollow } \\
\text { plastic window }\end{array}$ & 1300 \\
\hline Option Two & $\begin{array}{c}\text { Column net frame } \\
\text { structure }\end{array}$ & Plastic net window & 1900 \\
\hline Option Three & $\begin{array}{c}\text { Column net frame } \\
\text { structure }\end{array}$ & $\begin{array}{c}\text { Single frame double } \\
\text { glass hollow steel } \\
\text { window }\end{array}$ & 1750 \\
\hline
\end{tabular}

(1) Calculation function coefficient

For the evaluation of the scheme, the value engineering team used a combination of qualitative and quantitative methods to carefully analyze and compare the construction period and cost of each scheme, to meet the requirements of residents and the convenience of construction. The team also quantitatively analyzed each scheme. The functional evaluation coefficients of each scheme are calculated separately. The functional coefficients of option one is 0.301 ; the function coefficient of option two is 0.356 ; the function coefficient of option three is 0.344 .

(2) Calculated cost factor $C$

Cost factor $=$ unilateral cost per scenario $/$ unilateral cost of all scenarios

$$
\begin{aligned}
& C_{1}=1300 /(1300+1900+1750)=0.263 \\
& C_{2}=1900 /(1300+1900+1750)=0.384 \\
& C_{3}=1750 /(1300+1900+1750)=0.354
\end{aligned}
$$

(3) Calculated value coefficient $\mathrm{V}$

The value coefficient can be calculated by the formula $\mathrm{V}=F / C$. The calculation results are shown in Table 2. According to the principle that the value coefficient is higher, the higher the value of the scheme is, the optimal scheme is selected. After comparing the three schemes, the value coefficient of scheme 1 is the largest, which is obviously better than scheme 2 and scheme 3 . That is to say, scheme 1 has the highest capital utilization rate, so scheme one is the optimal scheme.

Table 2 Value coefficient calculation

\begin{tabular}{|c|c|c|c|}
\hline Program & $\begin{array}{c}\text { Functional } \\
\text { coefficient }\end{array}$ & $\begin{array}{c}\text { Cost } \\
\text { factor }\end{array}$ & $\begin{array}{c}\text { Value } \\
\text { factor }\end{array}$ \\
\hline Option One & 0.301 & 0.263 & 1.144 \\
\hline Option Two & 0.356 & 0.384 & 0.927 \\
\hline Option Three & 0.344 & 0.354 & 0.972 \\
\hline
\end{tabular}

The value engineering team conducted the value study of the three design schemes of the residential project, combined with the quantitative analysis method, and selected the Option one, which not only ensured the function and quality, but also effectively reduced the cost, so that make the project plan design play its due role. 


\section{Conclusions}

In summary, the cost control of construction projects is a highly technical and professional work, which runs through all stages of project implementation. In the whole process of project implementation, the design phase of the project should be the key stage for determining and controlling the total cost of the project. In order to ensure the smooth progress of the project, the design unit and the construction unit should cooperate closely, and through the selection of multiple plans, rationally select the building materials and construction plans to achieve the expected investment control objectives.

\section{References}

[1] Xiaoli Chen, 2015. Analysis of the application of value engineering in the design stage, Construction Economy. (05), pp. 105-107.

[2] Lingling Cheng, 2017. The Status Quo of Construction Engineering Cost Management and Its Countermeasures, Housing and Real Estate. (03), pp.42.

[3] Qunhui Liu, 2010. Application of Value Engineering in Engineering Scheme Design, Grain Science and Technology and Economy. (02), pp.37-38.

[4] Jianhua Ma, 2015. Cost control in the engineering design stage, Manager' Journal. (01), pp.280-281.

[5] Yan Wei, 2016. Discussion on Cost Control in the Stage of Architectural Design, Jiangxi Building Materials. (16), pp. $228+231$. 